\title{
BOUNDARY CONDITIONS IN A REAL BIPOLAR SEMICONDUCTOR-METAL JUNCTION
}

\author{
A. Konin \\ Semiconductor Physics Institute, A. Goštauto 11, LT-01108 Vilnius, Lithuania \\ E-mail: konin@pfi.lt
}

Received 16 March 2006

\begin{abstract}
Boundary conditions for non-equilibrium carrier densities and electric potential in a real metal-semiconductor junction are obtained on the basis of the continuity equations and the Poisson equation. The non-steady state case has been analysed. It is taken into account that holes do not penetrate into metal and the chemical potential of metal is constant. The both cases of open or loaded by a resistor external electric circuit are considered.
\end{abstract}

Keywords: boundary conditions, continuity equations, electric potential, metal-semiconductor junction

PACS: $73.40 . \mathrm{Sx}, 73.50 . \mathrm{Gr}$

\section{Introduction}

It is known that non-equilibrium electrons and holes in bipolar semiconductors have influence on formation of electromotive forces (emf) of various nature (Dember emf, Hall emf, thermo-emf, etc.) [1-3]. Usually every emf is measured across the metallic contacts placed on the sample surfaces. It is shown in $[1,2]$ that a distortion of energy bands [4] influences the Dember emf and the Hall emf values. For calculation of these electromotive forces it is necessary to use the boundary conditions (BCs) in a real metal-semiconductor junction (MSJ). The BCs in quasi-neutrality approximation have been obtained in [5]. Owing to quasi-neutrality approximation the BCs have been formulated at a virtual surface, which is disposed at a distance of several Debye lengths from the real MSJ. It is obvious that the BCs [5] do not take into account a non-equilibrium space charge region (screening mode [6]) influence on emf formation.

This article is aimed at the formulation of the BCs in a real metal-semiconductor junction.

\section{Theory}

Let us consider a metal-semiconductor junction (MSJ), which lies at $x=0$. We assume that a metal is to the left of $x=0$ and a semiconductor to the right.
BCs are derived on the basis of the continuity equations $[4,7]$ and the Poisson equation:

$$
\begin{gathered}
\frac{\partial \delta n}{\partial t}=\frac{1}{e} \frac{\partial j_{n}}{\partial x}-R+G, \\
\frac{\partial \delta p}{\partial t}=-\frac{1}{e} \frac{\partial j_{p}}{\partial x}-R+G, \\
\frac{\partial^{2} \delta \varphi}{\partial x^{2}}=\frac{e}{\varepsilon \varepsilon_{0}}(\delta n-\delta p),
\end{gathered}
$$

where $\delta n(\delta p)$ is the non-equilibrium electron (hole) density, $-e$ is the electron charge, $j_{n}\left(j_{p}\right)$ is the electron (hole) current density, $R(G)$ is the carriers bulk recombination (generation) rate, $\varepsilon$ is the semiconductor electrical permittivity, and $\varepsilon_{0}$ is the vacuum permittivity.

In the common case the partial current densities have the form

$$
\begin{aligned}
& j_{n}=-\sigma_{n}\left(\frac{\partial \delta \tilde{\varphi}_{n}}{\partial x}-\theta_{n}\right), \\
& j_{p}=-\sigma_{p}\left(\frac{\partial \delta \tilde{\varphi}_{p}}{\partial x}-\theta_{p}\right),
\end{aligned}
$$

where $\sigma_{n}\left(\sigma_{p}\right)$ is the electron (hole) electric conductivity, $\delta \tilde{\varphi}_{n}=\delta \varphi-\delta F_{n} / e$ is the non-equilibrium electrochemical potential of electrons, $\delta \tilde{\varphi}_{p}=\delta \varphi+\delta F_{p} / e$ is the non-equilibrium electrochemical potential of holes, and $\delta F_{n}\left(\delta F_{p}\right)$ is the electron (hole) non-equilibrium chemical potential. 
The expression of $\theta_{n, p}$ depends on the field acting on the semiconductor. If the temperature gradient arises along the $x$ axis, then

$$
\theta_{n}=-\alpha_{n} \frac{\mathrm{d} T_{n}}{\mathrm{~d} x}, \quad \theta_{p}=-\alpha_{p} \frac{\mathrm{d} T_{p}}{\mathrm{~d} x},
$$

where $T_{n, p}$ is the electron (hole) temperature and $\alpha_{n, p}$ is the thermo-emf coefficient.

If the electric $E_{y}$ and magnetic $B_{z}$ fields act on a sample, then

$$
\theta_{n}=-\gamma_{n} \mu_{n} E_{y} B_{z}, \quad \theta_{p}=\gamma_{p} \mu_{p} E_{y} B_{z},
$$

where $\mu_{n, p}$ is the mobility of the carriers and $\gamma_{n, p}$ is the Hall factor of electrons or holes.

If a sample is illuminated by absorbed light, or when the electric field acts on a sample, then $\theta_{n, p}=0$.

Let us consider now the case of open external electric circuit.

Integrating Eqs. (1), (2) with respect to $x$ in a short range from $x=-\nu$ to $x=\nu$ and taking the limit one obtains

$$
\begin{aligned}
& j_{n}(+0)-j_{n}(-0)=e\left(R_{S}-G_{S}\right), \\
& j_{p}(+0)-j_{p}(-0)=-e\left(R_{S}-G_{S}\right) .
\end{aligned}
$$

The absence of surface recombination in metal has been taken into account while deriving Eq. (5). Therefore generation and recombination rates have the form

$$
R=R_{S} \delta(x-0), \quad G=G_{S} \delta(x-0),
$$

where $\delta(x)$ is the delta function, $G_{S}$ is the surface generation rate, and $R_{S}$ is the surface recombination rate (SRR).

We can simplify Eq. (5) because there are no holes in the metal $\left(j_{p}(-0)=0\right)$ and the electric circuit is open $\left(j_{n}(-0)=0\right.$ ). From Eq. (5) we obtain

$$
\begin{aligned}
& j_{n}(+0)=e\left(R_{S}-G_{S}\right), \\
& j_{p}(+0)=-e\left(R_{S}-G_{S}\right) .
\end{aligned}
$$

The BCs (7) have been obtained in [6] for the case of negligible surface generation rate.

In the first approximation by non-equilibrium carrier densities the bulk recombination rate has the form [7]

$$
R=\frac{\delta n}{\tau_{n}}+\frac{\delta p}{\tau_{p}},
$$

where $\tau_{n}\left(\tau_{p}\right)$ is the time characterizing electron (hole) bulk recombination rate. It is obvious that in this case the SRR is equal to

$$
R_{S}=S_{n} \delta n(+0)+S_{p} \delta p(+0),
$$

where $S_{n, p}$ are the parameters characterizing SRR.

Note that in considered model the MSJ means the layer of thickness much smaller than the Debye length [1]. Therefore the parameters $S_{n, p}$ characterize SRR in the real MSJ. The BCs in [6] owing to quasi-neutrality approximation are obtained at virtual surface, which is disposed at a distance of several Debye lengths from the real MSJ.

Let us now integrate the Poisson equation (3) with respect to $x$ from $-\nu$ to $\alpha$ and with respect to $\alpha$ from $-\nu$ to $\nu$ and take the limit $\nu \rightarrow 0$. One obtains

$$
\begin{aligned}
\delta \varphi(+0)-\delta \varphi_{\mathrm{M}}= & 2 \lim _{\nu \rightarrow 0} \nu \frac{\mathrm{d} \delta \varphi(-\nu)}{\mathrm{d} \nu} \\
& +\lim _{\nu \rightarrow 0} \int_{-\nu}^{\nu} \mathrm{d} \alpha \int_{-\nu}^{\alpha} \frac{\delta n-\delta p}{\varepsilon \varepsilon_{0}} \mathrm{~d} x,
\end{aligned}
$$

where $\delta \varphi_{\mathrm{M}}$ is the variation of electric potential of metallic contact. Note that there are no electric field in metal $(\mathrm{d} \delta \varphi(-\nu) / \mathrm{d} \nu=0)$ and the function $(\delta n-$ $\delta p) /\left(\varepsilon \varepsilon_{0}\right)$ is finite. Therefore we derive from Eq. (9)

$$
\delta \varphi(+0)=\delta \varphi_{\mathrm{M}} .
$$

Integrating Eq. (1) with respect to $x$ from $\alpha$ to $\nu$ with the use of Eq. (4) we derive

$$
\begin{aligned}
j_{n}(\nu) \sigma_{n}^{-1}(\alpha)= & -\frac{\mathrm{d} \delta \tilde{\varphi}(\alpha)}{\mathrm{d} \alpha}+Q_{n} \\
& +e \sigma_{n}^{-1}(\alpha) \int_{\alpha}^{\nu}(R-G) \mathrm{d} x .
\end{aligned}
$$

Let us integrate Eq. (11) with respect to $\alpha$ from $-\nu$ to $\nu$ and take the limit $\nu \rightarrow 0$. One obtains

$$
\begin{aligned}
j_{n}(+0)= & \sigma_{n S}\left[\delta \tilde{\varphi}_{n}(-0)-\delta \tilde{\varphi}_{n}(+0)\right] \\
& +e\left(R_{S}-G_{S}\right),
\end{aligned}
$$

where $\sigma_{n S}^{-1}=\lim _{\nu \rightarrow 0} \int_{-\nu}^{\nu} \sigma_{n}^{-1} \mathrm{~d} \alpha, \sigma_{n S}$ is the electron surface conductivity.

By analogy we derive from Eq. (2)

$$
\begin{aligned}
j_{p}(+0)= & \sigma_{p S}\left[\delta \tilde{\varphi}_{p}(-0)-\delta \tilde{\varphi}_{p}(+0)\right] \\
& -e\left(R_{S}-G_{S}\right),
\end{aligned}
$$

where $\sigma_{p S}^{-1}=\lim _{\nu \rightarrow 0} \int_{-\nu}^{\nu} \sigma_{p}^{-1} \mathrm{~d} \alpha, \sigma_{p S}$ is the hole surface conductivity.

Integrating Eqs. (1) and (2) with respect to $x$ from $-\nu$ to $\alpha$ and with respect to $\alpha$ from $-\nu$ to $\nu$ and taking the limit $\nu \rightarrow 0$, one obtains for the left of $x=0$

$$
j_{n}(-0)=\sigma_{n S}\left[\delta \tilde{\varphi}_{n}(-0)-\delta \tilde{\varphi}_{n}(+0)\right],
$$




$$
j_{p}(-0)=\sigma_{p S}\left[\delta \tilde{\varphi}_{p}(-0)-\delta \tilde{\varphi}_{p}(+0)\right] .
$$

Subtracting Eq. (14) from Eq. (12) and Eq. (15) from Eq. (13) we obtain Eq. (5) as it should be. From condition $j_{p}(-0)=0$ (there are no holes in the metal) and Eq. (14) we derive that $\sigma_{p S}=0$. It follows from Eq. (14) and condition $j_{n}(-0)=0$ that

$$
\delta \tilde{\varphi}_{\mathrm{M}}=\delta \varphi(+0)-\frac{1}{e} \delta F_{n}(+0) .
$$

Taking into account that the chemical potential of the metal has not changed, we derive from Eqs. (10) and (16)

$$
\delta F_{n}(+0)=0 .
$$

It follows from Eqs. (7), (8), (10), and (11) that BCs for $\delta n, \delta p$, and $\delta \varphi$ take the form

$$
\begin{gathered}
\frac{1}{e} j_{p}(+0)=-S_{p} \delta p(+0)+G_{S}, \\
\delta \varphi_{\mathrm{M}}=\delta \varphi(+0), \\
\delta n(+0)=0 .
\end{gathered}
$$

In the case of loaded external circuit the electric current $j_{0}=j_{n}(-0)$ flows through metallic contact. Then we obtain from Eq. (14)

$$
\delta \varphi_{\mathrm{M}}=\delta \varphi(+0)+\frac{j_{0}}{\sigma_{n S}} .
$$

The BCs (18) and (20) remain the same. Equation (21) has a simple physical sense: the electric potential step at MSJ is caused by electric current through the junction and electron surface conductivity. In the case of open external circuit, BC (21) transforms into BC (19) as it should be. The BCs (18)-(21) differ on principle from those obtained in quasi-neutrality approximation [6], because they are formulated in a real MSJ.
Note that BCs (20) and (21) are correct for nonequilibrium density and potential of any value. The BC for the hole (electron) current in the common case takes the form of Eq. (7).

Also it should be stressed that obtained $\mathrm{BCs}$ require the exact solution of continuity equations and the Poisson equation.

\section{Conclusion}

The boundary conditions for the non-equilibrium carrier densities and electric potential in a real metalsemiconductor junction are obtained. The exact solution of the continuity equations and the Poisson equation together with the boundary conditions permit one to take into account the metallic contact influence on the formation of emf of various nature (Hall emf, Dember emf, thermo-emf, etc.).

\section{References}

[1] A. Konin, Lithuanian J. Phys. 45, 373 (2005).

[2] A. Konin, Semiconductors 40 (2006, in press).

[3] Yu.G. Gurevich, G.N. Logvinov, I.N. Volovichev, G. Espejo, O.Yu. Titov, and A. Meriuts, Phys. Status Solidi B 231, 278 (2002).

[4] V.L. Bonch-Bruevich and S.G. Kalashnikov, Fizika Poluprovodnikov (Nauka, Moscow, 1977) [Physics of Semiconductors, in Russian].

[5] M. Krčmar and W.M. Saslow, Phys. Rev. B 65, 2333131 (2002).

[6] O.Yu. Titov, J. Giraldo, and Yu.G. Gurevich, Appl. Phys. Lett. 80, 3108 (2002).

[7] I.N. Volovichev and Yu.G. Gurevich, Semiconductors 35, 306 (2001).

\title{
KRAŠTINĖS SĄLYGOS REALIOJE BIPOLINIO PUSLAIDININKIO IR METALO SANDŪROJE
}

\author{
A. Konin \\ Puslaidininkiu fizikos institutas, Vilnius, Lietuva
}

\footnotetext{
Santrauka

Nustatytos kraštinès sąlygos nepusiausviriniams elektriniam potencialui ir krūvininkų koncentracijai realioje metalo ir puslaidininkio sandūroje remiantis nenutrūkstamumo ir Poisson'o lygtimis.
}

Ištirtas nestacionarios būsenos atvejis. Atsižvelgta į tai, kad metalo cheminis potencialas yra konstanta ir metale nèra skylių. Išorinė elektros grandiné gali būti atvira arba apkrauta omine varža. 